\title{
Crack Risk Evaluation of Early Age Concrete Based on the Distributed Optical Fiber Temperature Sensing
}

\author{
Nannan Shi, ${ }^{1}$ Yanyu Chen, ${ }^{2}$ and Zhenbao Li ${ }^{1}$ \\ ${ }^{1}$ College of Architecture and Civil Engineering, Beijing University of Technology, Beijing 100124, China \\ ${ }^{2}$ Department of Mechanical Engineering, State University of New York at Stony Brook, Stony Brook, NY 11794, USA \\ Correspondence should be addressed to Zhenbao Li; lizb@bjut.edu.cn
}

Received 29 March 2016; Accepted 31 July 2016

Academic Editor: Belal F. Yousif

Copyright (c) 2016 Nannan Shi et al. This is an open access article distributed under the Creative Commons Attribution License, which permits unrestricted use, distribution, and reproduction in any medium, provided the original work is properly cited.

\begin{abstract}
Cracks often appear in concrete arch dams, due to the thermal stress and low tensile strength of early age concrete. There are three commonly used temperature controlling measures: controlling the casting temperature, burying cooling pipe, and protecting the surface. However, because of the difficulty to obtain accurate temperature and thermal stress field of the concrete, the rationality and economy of these measures are not assessed validly before and after construction. In this paper, a crack risk evaluation system for early age concrete is established, including distributed optical fiber temperature sensing (DTS), prediction of temperature and stress fields, and crack risk evaluation. Based on the DTS temperature data, the back-analysis method is applied to retrieve the thermal parameters of concrete. Then, the temperature and thermal stress of early age concrete are predicted using the reversed thermal parameters, as well as the laboratory test parameters. Finally, under the proposed cracking risk evaluation principle, the cracking risk level of each concrete block is given; the preliminary and later temperature controlling measures were recommended, respectively. The application of the proposed system in Xiluodu super high arch dam shows that this system works effectively for preventing cracks of early age concrete.
\end{abstract}

\section{Introduction}

Cracks often appear in mass concrete structures, such as concrete dams. Some of the cracks are due to the unreasonable structural design, uneven settlement of the structure, and/or the poor quality of concrete. However, most of the cracks are caused by the thermal stress $[1,2]$. Particularly, thermal stress easily causes cracks, since the tensile strength of early age concrete is quite low. Cracks not only destroy the beauty of the dams but also affect durability of the concrete; what is more, severe concrete cracks may affect the normal use and dam safety.

To reduce concrete cracks and improve integrity of the structures, temperature controlling measures are performed during construction, such as controlling the casting temperature, burying cooling pipe, and protecting the concrete surface. Practices show that these measures work effectively to reduce the concrete cracks in arch dams. However, because of the difficulty to obtain accurate temperature and thermal stress field of the concrete, the rationality and economy of these measures were not assessed validly before and after construction. In order to obtain internal temperature process of the concrete, the easiest and most straightforward way is to bury thermometers within the concrete, while, due to the limited number of measuring points, the poor reliability of human-read data, the interference caused by construction, and so forth, it is nearly impossible to obtain the exact temperature process of the concrete. With the development of optical fiber communication technology, distributed optic fiber temperature sensing (DTS) has been applied in the leakage monitoring of petroleum pipelines, HV power cable temperature monitoring, and concrete temperature monitoring of dams, because it has series of advantages, such as more measuring points, higher sensitivity, and lower cost of unit temperature information and real-time monitoring $[3,4]$. Practices show that DTS can capture temperature process 
more realistically. Currently, to obtain the exact thermal stress of concrete, thermal stress measuring machine is often applied to test the thermal stress of small size specimens in the laboratory [5]. However, in practical project, software, based on the FEM, is often applied to simulate the temperature and thermal stress of concrete [6-8]. Since most of the concrete thermal parameters used in the simulation refer to similar projects or are based on laboratory test results, there are some discrepancies between the real parameters and the applied parameters, which lead to the inaccuracy of the simulation results.

In this paper, a crack risk evaluation system for the early age concrete is established, including the following aspects: firstly, in order to obtain adequate and more accurate temperature data, the internal temperature process of the concrete is monitored by DTS; secondly, a back-analysis method is applied to retrieve concrete thermal parameters for the prediction of temperature and thermal stress under different temperature controlling measures; thirdly, the standard value of the concrete splitting tensile strength is obtained by laboratory test; fourthly, a crack risk evaluation principle is established. Finally, when the temperature and thermal stress are predicted, combined with the established principle, the preliminary and later temperature controlling measures were recommended, respectively, which are implemented as provisions for concrete construction to reduce cracks.

\section{The Crack Risk Evaluation System and Related Theories}

2.1. Description of the System. The aim of this system is giving preliminary and reasonable temperature controlling measures before construction and proposing temperature controlling measures of early age concrete for possible factors which may lead to crack after construction. Figure 1 shows the crack risk evaluation system flow chart.

To achieve the real-time online monitoring of the concrete temperature, DTS is introduced to monitor the temperature process of the typical dam blocks. First, a monitoring room is settled at the construction site to achieve the permanent and close observation. Second, the measured temperature process data of typical points are selected as the input data for thermal parameters back-analysis. Third, the retrieved thermal parameters are used to perform feedback analysis, through comparing the DTS measured data with the calculated data using the reversed thermal parameters, and this process is a loop until the error of the two sets of data is acceptable.

After getting the reliable thermal parameters and before the new concrete block is casted, the temperature and thermal stress are predicted under the possible temperature controlling measures.

To determine the rationality of temperature control measures, the tensile strength of the concrete is also needed. In this paper, the splitting test of concrete is performed in the laboratory to obtain the splitting tensile strength.

A crack risk evaluation principle is established, which includes two indicators. One is the allowed maximum temperature of concrete. If the maximum temperature is too high, the temperature gradient of internal and external of the concrete is also large, which may lead to cracks of concrete. Besides, the temperature drop amplitude from maximum temperature to the annual average temperature is also notable, which may lead to cracks as well, since the maximum temperature of concrete often occurs in 3-5 days of age. Therefore, the allowed maximum temperature is one indicator of crack risk evaluation principle; the other indicator is the anticrack safety factor of concrete, the calculation method and the suggested range of which can be obtained from the Design Code for Concrete Arch Dam (China DL/T5346-2006).

When the temperature process, thermal stress process, and the splitting tensile strength are obtained, the preliminary temperature and crack control measure are proposed under the crack risk evaluation principle.

After the new concrete block is set, considering the possible factors, such as cold wave, rain storm, and solar radiation, which may result in cracks, the temperature and thermal stress are also predicted in order to recommend corresponding temperature controlling measures.

\subsection{Related Theories}

2.2.1. Distributed Optical Fiber Sensing Principle. DTS is primarily based on temperature effect of Raman backscattering light and Optical Time Domain Reflectometry (OTDR) principle [9]. The Raman backscattering light has two components: stokes and antistokes components. Antistokes light intensity is particularly sensitive for temperature change and the intensity is modulated by temperature, while the stokes light is not relevant to temperature. The intensity ratio of antistokes to stoke signals from a constant optical pulse can be related to the temperature measurements as given by (1) $[9,10]$. Combined with internal reference temperature of the equipment and an externally determined calibration function for the particular fiber type, the temperature value can be determined. According to relationship between the speed of light and time, expressed as (2) [9, 10], the precise position of measuring points along optical fiber can be located. Thus, the temperature and the position of measuring point can be determined using DTS.

$$
\frac{I_{a}}{I_{s}}=\left\{\frac{\left(x_{0}+x_{k}\right)^{4}}{\left(x_{0}-x_{k}\right)^{4}}\right\} \exp \left(-h \cdot c \cdot \frac{x_{k}}{\kappa T}\right),
$$

where $I_{a}$ and $I_{s}$ are the light intensity of antistokes and stokes, respectively; $x_{0}$ and $x_{k}$ are wave number of incident light in different energy levels; $h$ is the Planck constant; $c$ is the light speed in optical fiber; $\kappa$ is the Boltzmann constant; and $T$ is the absolute temperature.

$$
d=c_{0} \cdot \frac{t}{2 n}
$$

where $d$ is the distance from the emission site of the scattering light to the incident side; $c_{0}$ is the speed of light in vacuum; $t$ is the time of incident light returning to optical fiber incident side; and $n$ is the refractive index of optical fiber. 


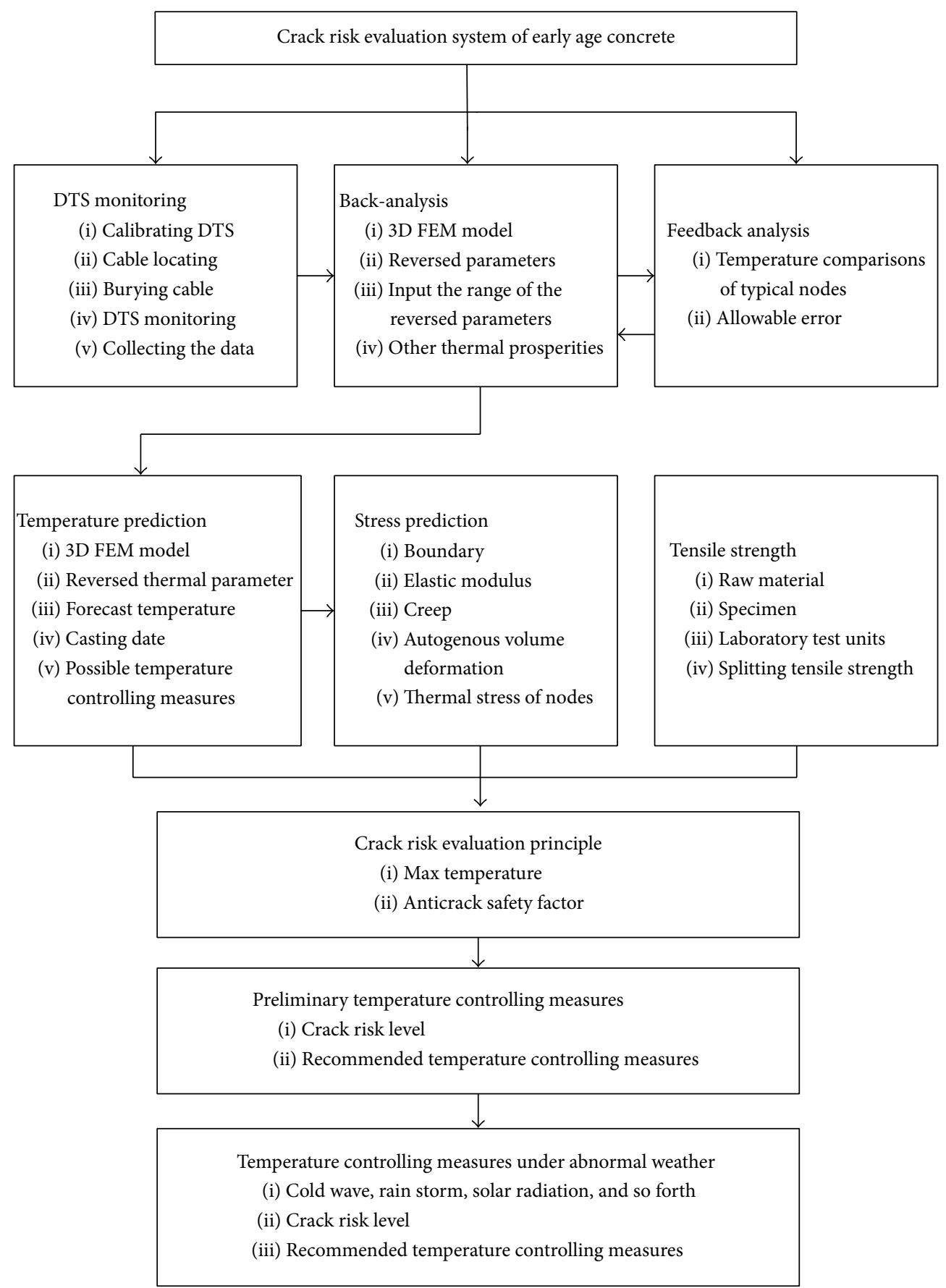

FIGURE 1: Flow chart of the crack risk evaluation system.

2.2.2. Principle of $3 D$ Unsteady Temperature Field [1]. In computational domain $R$, unsteady temperature field $T(x, y, z, t)$ satisfies the heat conduction equation:

$$
\frac{\partial T}{\partial t}=a\left(\frac{\partial^{2} T}{\partial x^{2}}+\frac{\partial^{2} T}{\partial y^{2}}+\frac{\partial^{2} T}{\partial z^{2}}\right)+\frac{\partial \theta}{\partial \tau},
$$

where $T$ is the temperature, ${ }^{\circ} \mathrm{C}$; $t$ is the time, $\mathrm{d}$; $a$ is the thermal diffusivity, $\mathrm{m}^{2} / \mathrm{d} ; \theta$ is adiabatic temperature rise of concrete, ${ }^{\circ} \mathrm{C}$; and $\tau$ is the age, $\mathrm{d}$.
According to the Variational Principle, 3D unsteady temperature field is solved by the following functional equation:

$$
\begin{aligned}
& I(T)=\iiint_{R}\left\{\frac{1}{2}\left[\left(\frac{\partial T}{\partial x}\right)^{2}+\left(\frac{\partial T}{\partial y}\right)^{2}+\left(\frac{\partial T}{\partial z}\right)^{2}\right]\right. \\
& \left.\quad-\frac{1}{a}\left(\frac{\partial \theta}{\partial \tau}-\frac{\partial T}{\partial \tau}\right) T\right\} d x d y d z \\
& \quad+\iint_{C} \frac{\beta}{\lambda}\left(\frac{T}{2}-T_{a}\right) T d s,
\end{aligned}
$$


where $R$ is the computational domain; $T$ is the temperature; $a$ is the thermal diffusivity; $\theta$ is adiabatic temperature rise; $\lambda$ is the thermal conductivity; $\beta$ is the surface heat transfer coefficient; $T_{a}$ is outside temperature; $t$ is the time; $\tau$ is the age; and $C$ is the third boundary condition. By the stationary value condition $\delta I / \delta T=0$ and backward difference for time domain, the governing equation of FEM calculation for temperature field is obtained:

$$
\left[[H]+\frac{1}{\Delta t_{n}}[R]\right]\left\{T_{n+1}\right\}-\frac{1}{\Delta t_{n}}[R]\left\{T_{n}\right\}+\left\{F_{n+1}\right\}=0,
$$

where $[H]$ is the matrix of heat conduction; $[R]$ is the supplemental matrix of heat conduction; $T_{n}$ and $T_{n+1}$ are the arrays of node temperature; and $F_{n+1}$ is the array of node temperature load. According to (5), $\left\{T_{n+1}\right\}$ can be derived from $\left\{T_{n}\right\}$.

2.2.3. Principle of Cooling Pipe. According to Fourier Law of Heat Conduction and heat balance, the accurate FEM method for pipe cooling was given by Zhu [1]. Because of the large temperature gradient around the cooling pipe, grid must be densely arranged, which results in the complexity of modeling and large complexity of computation. In this paper, the equivalent equation of heat conduction to consider pipe cooling proposed by Zhu [1] is adopted. The pipe cooling is considered as the negative heat source and cooling effect of pipes is considered from a mean sense.

2.2.4. Principle of Back-Analysis of Thermal Parameters. The error $E_{r}$ between the measured temperature data and the calculated temperature data is defined as the objective function, and thermal parameters $\alpha, \beta, \theta_{0}, a$, and $b$ are selected as optimal design variables. The specific mathematical model can be expressed as follows:

$$
\begin{aligned}
& E_{r}=\min F(X)=\min \sum_{j=1}^{m} \sum_{i=1}^{n}\left(T_{i j}^{c}-T_{i j}^{m}\right)^{2}, \\
& X=\left[x_{1}, x_{2}, x_{3}, x_{4}, x_{5}\right]^{T}=\left[\alpha, \beta, \theta_{0}, a, b\right]^{T} .
\end{aligned}
$$

The constraint condition is

$$
a_{i} \leq x_{i} \leq b_{i}, \quad(i=1,2,3,4,5),
$$

where $T_{i j}^{c}$ is the calculated temperature value of node $j$ at $i$ moment; $T_{i j}^{m}$ is the measured temperature value of node $j$ at $i$ moment; $m$ is the total number of measuring points; and $n$ is the vector number of observation time series. The optimization model is constraint nonlinear programming. The solving methods of the model are Complex Method, Penalty Function Method, Feasible Direction Method, and so forth. As there are only a few optimization parameters, considering the accuracy and solving speed, Complex Method is adopted in this paper.

2.2.5. Principle of Elastic Creep Thermal Stress Field [1]. In a complex stress state, concrete strain increment often includes the elastic strain increment, the elastic creep increment, the autogenous volume strain increment, and the dry shrinkage strain increment. The formula is expressed as

$$
\left\{\Delta \varepsilon_{n}\right\}=\left\{\Delta \varepsilon_{n}^{e}\right\}+\left\{\Delta \varepsilon_{n}^{c}\right\}+\left\{\Delta \varepsilon_{n}^{T}\right\}+\left\{\Delta \varepsilon_{n}^{o}\right\}+\left\{\Delta \varepsilon_{n}^{s}\right\}
$$

where $\left\{\Delta \varepsilon_{n}^{e}\right\}$ is the elastic strain increment; $\left\{\Delta \varepsilon_{n}^{c}\right\}$ is the creep strain increment; $\left\{\Delta \varepsilon_{n}^{T}\right\}$ is the temperature strain increment; $\left\{\Delta \varepsilon_{n}^{o}\right\}$ is the autogenous volume strain increment; and $\left\{\Delta \varepsilon_{n}^{s}\right\}$ is the dry shrinkage strain increment.

The FEM governing equation is obtained in region $R$ in any time period by geometric equations, physical equations, and balance equations, expressed as

$$
\begin{aligned}
{[K]\left\{\Delta \delta_{n}\right\}=} & \left\{\Delta P_{n}\right\}^{L}+\left\{\Delta P_{n}\right\}^{C}+\left\{\Delta P_{n}\right\}^{T}+\left\{\Delta P_{n}\right\}^{O} \\
& +\left\{\Delta P_{n}\right\}^{S},
\end{aligned}
$$

where $[K]$ is the global stiffness matrix; $\left\{\Delta \delta_{n}\right\}$ is the displacement increment of all nodes in three directions in region $R$; and $\left\{\Delta P_{n}\right\}^{L},\left\{\Delta P_{n}\right\}^{C},\left\{\Delta P_{n}\right\}^{T},\left\{\Delta P_{n}\right\}^{O}$, and $\left\{\Delta P_{n}\right\}^{S}$ are the equivalent nodal force increments in $\Delta t_{n}$ caused by the external load, creep, temperature change, autogenous volume strain, and dry shrinkage.

Based on the temperature and thermal stress calculation theories mentioned above, FZFX3D, a three-dimensional FEM program, was developed for the temperature and thermal stress prediction.

\subsubsection{Crack Risk Evaluation Principle}

(1) Allowed Maximum Temperature. To determine the maximum allowed temperature of the concrete, the following factors should be considered: the temperature gradient between internal and external of the concrete, the temperature drop amplitude from maximum temperature to the annual average temperature, the width of transverse joints needed for grouting, and the maturity of early age concrete. The calculation method of the maximum allowed temperature of the concrete was given in [1].

(2) Anticrack Safety Factor. The calculation method, as expressed in (10), is given by Design Specification for Concrete Arch Dams. In (10), the range of $K$ is usually 1.52.0. According to the range of $K$, the crack risk level of the concrete is divided into four types and the comments and suggestions of temperature controlling measure of each crack risk level are tabulated in Table 1.

$$
\sigma \leq \frac{f_{t k}}{K}
$$

where $f_{t k}$ is the tensile strength of the concrete and $K$ is the anticrack safety factor.

\section{Application of the System}

3.1. Description of the Project. Xiluodu hydropower station is located in the Jinshajiang River Grand Canyon. The concrete 
TABLE 1: Crack risk evaluation level under different anticrack safety factor.

\begin{tabular}{|c|c|c|c|}
\hline Crack risk level & $K$ & Evaluation results & Analysis and possible solutions \\
\hline I & $>2.0$ & Quite safe & $\begin{array}{l}\text { (i) Due to the strict temperature controlling measures, the minimum stress ratio is } \\
\text { quite high, which means the low level of crack risk. } \\
\text { (ii) The high value of the minimum stress ratio may increase the cost of temperature } \\
\text { controlling. }\end{array}$ \\
\hline II & $1.5-2.0$ & Acceptable & $\begin{array}{l}\text { (i) The minimum stress value means the crack risk is under control according to the } \\
\text { code of arch dam. } \\
\text { (ii) No additional temperature controlling measures are needed and the proposed } \\
\text { temperature controlling is highly recommended. }\end{array}$ \\
\hline III & $1.0 \sim 1.5$ & Unacceptable & $\begin{array}{l}\text { (i) Since this project is classified into the first level structures, this stress ratio may } \\
\text { lead to possible potential risk of the dam block. } \\
\text { (ii) The preliminary temperature measures are acceptable, but additional measures } \\
\text { are needed. }\end{array}$ \\
\hline IV & $<1.0$ & High risk & $\begin{array}{l}\text { (i) The value of minimum stress ratio is quite low compared with that of Code of } \\
\text { Arch Dam, which may lead to potential failure of the dam. } \\
\text { (ii) The proposed temperature controlling measures are totally unacceptable, and } \\
\text { the restudy is needed. }\end{array}$ \\
\hline
\end{tabular}

arch dam is $285.50 \mathrm{~m}$ in height. The total volume of concrete, needed for temperature controlling, is 6.34 million $\mathrm{m}^{3}$. Since installed capacity of Xiluodu hydropower station ranks third in the world, there is a high requirement for the quality, appearance, and safety of the dam. The dam is located in the humid climate zone of midsubtropics, where the winter is dry and mild, and the summer is hot and rainy. The importance of the concrete dam and the special climatic condition determine that it is an arduous task to prevent the concrete crack.

15\#-09 and 15\#-10 (15\# denotes the dam section number; 09 or 10 denotes the block number) are taken as examples to introduce the application process of crack risk evaluation system.

\subsection{Back-Analysis of Concrete Thermal Parameters}

3.2.1. DTS Calibration and Monitoring Results. To achieve the real-time online temperature monitoring of the concrete, the Sentinel-DTS produced by UK Sensor Net Company is adopted in the project. Its temperature measurement resolution, measurement accuracy, and measurement range are $0.01^{\circ} \mathrm{C}, 0.1^{\circ} \mathrm{C}$, and $-60^{\circ} \mathrm{C}-200^{\circ} \mathrm{C}$, respectively. The optical fiber cable is buried in four dam sections (5\#, 15\#, 16\#, and 23\#) and the planning burying length of cable is $13500 \mathrm{~m}$.

To ensure that the temperature data is more accurate along the entire cable, the DTS must be calibrated. The optical fiber cable is put into the thermostat and then the optical fiber measured values are compared with the reference thermometer value. At the same time, temperature parameters of DTS are configured. Figure 2 shows the setup of the calibration experiment. A $35 \mathrm{~m}$ optical fiber is put into the thermostat for the field calibration in this experiment. Figure 3 shows that the main experimental apparatus DTS system consists of the T-Laser DTS unit and optical cable. Figure 4 shows a comparison diagram of the temperature distribution after

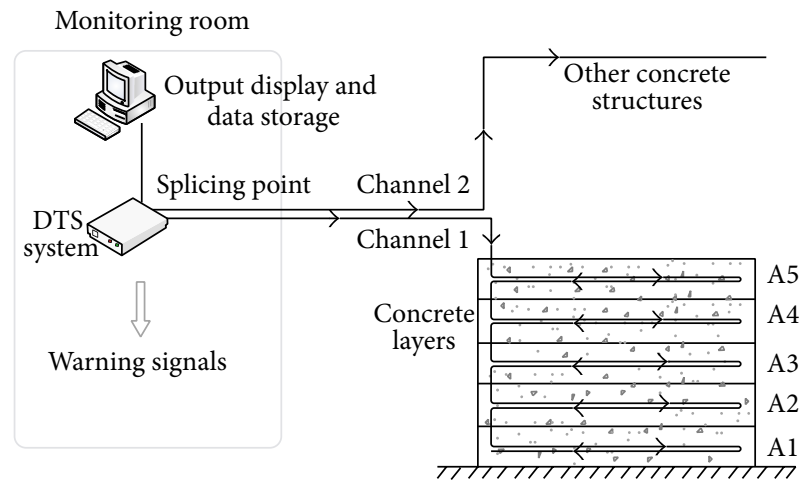

FIgURE 2: Diagram of DTS calibration and cable burying.

DTS calibration and the temperature displayed by the thermostat. It can be seen from Figure 4 that the space location resolution is $1 \mathrm{~m}$, and the error range is within $\pm 0.50^{\circ} \mathrm{C}$, which is acceptable because of some uncertain factors, such as the disturbance of the external construction environment on DTS and the space accuracy of selected measuring points.

15\#-09 was casted in October 18, 2009. The concrete strength grade is $\mathrm{C}_{180} 40$, and its mix proportion is shown in Table 2. Part of thermal parameters and mechanical parameters obtained from lab experiment is tabulated in Table 3. After DTS is calibrated, an $80 \mathrm{~m}$ long duplex cable is buried in the middle of 15\#-09 (elevation direction) to achieve the real-time online temperature monitoring of the concrete. Figure 5 shows the burying position of cable and location of analysis nodes. Figures 6 and 7 show the burying process of the cable and the temperature process of the concrete measured by DTS. It can be seen from Figure 7 that the internal temperature of the concrete experiences rising and drop and then tends to be stable. The maximum temperature occurs in 3-5 days. Since the duplex fiber is buried, the 


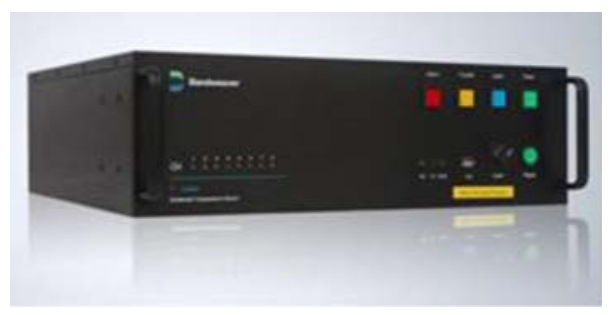

(a)

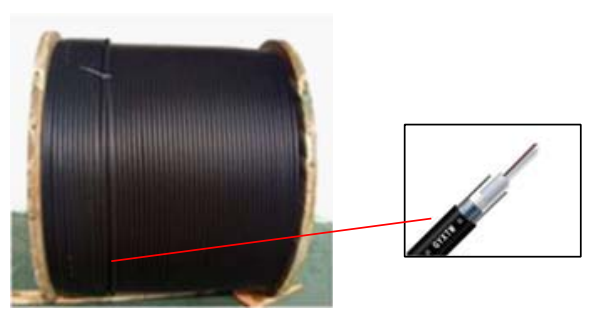

(b)

FIgUre 3: Components of DTS: (a) the DTS unit-T-Laser; (b) the optical cable.

TABLE 2: Mix proportion of dam concrete.

\begin{tabular}{|c|c|c|c|c|c|c|c|c|}
\hline \multirow{3}{*}{$W / C(\%)$} & \multirow{3}{*}{ Cement type } & \multirow{3}{*}{$S / A(\%)$} & \multicolumn{6}{|c|}{ Unit content $\left(\mathrm{kg} / \mathrm{m}^{3}\right)$} \\
\hline & & & \multirow{2}{*}{$W$} & \multirow{2}{*}{ C } & \multirow{2}{*}{$S$} & \multirow{2}{*}{ G } & \multicolumn{2}{|c|}{ Admixture } \\
\hline & & & & & & & WR & $\mathrm{AE}$ \\
\hline 63 & PMH42.5 & $35 \%$ & 81 & 129 & 361 & 1144 & 0.6 & 0.013 \\
\hline
\end{tabular}

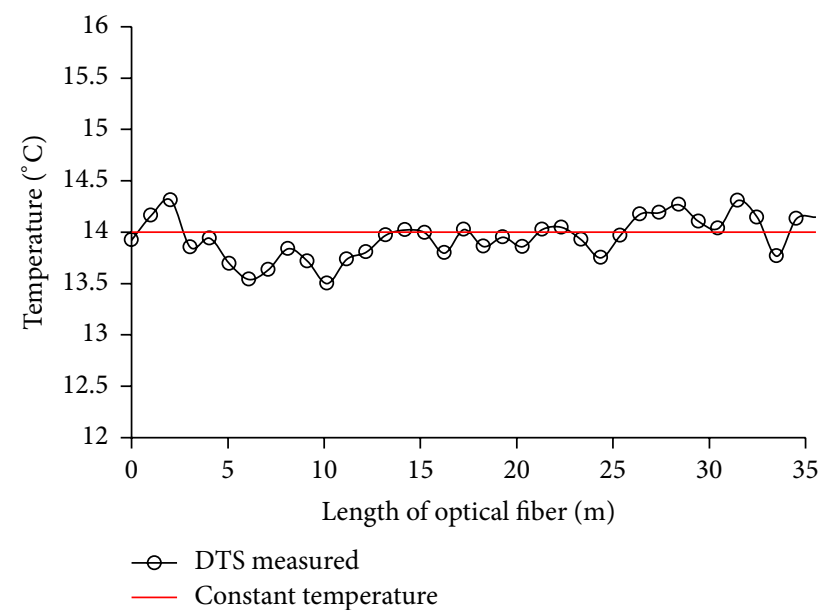

FIGURE 4: Comparison of DTS measured temperature and constant temperature of thermostat.

cloud picture of the temperature process is symmetric in Figure 7. As shown in Figure 8, the monitoring room which the computer and the DTS unit were placed in was fixed on the mountainside that was above the top water level of the reservoir. The embedment plane of the optical cable rose with the continuous placement of concrete in layers. The middle plane of concrete block was generally chosen as the embedment plane to measure the maximum temperature of the block. The temperature of all concrete blocks in left pier was monitored by optical cable. The optical cable embedded in middle plane of concrete blocks was typically configured in $S$ shape, as shown in Figure 9. The optical cables were fastened in the middle plane of the concrete block as shown in Figure 10.

3.2.2. The Results of the Back-Analysis. Figure 11 shows the present image of Xiluodu Dam and the corresponding 3D
FEM model. To reduce computational complexity, the dam sections of $14 \#$ and 16\# are only considered when the backanalysis for the thermal parameters of $15 \#-09$ concrete is performed. The FEM model has 239682 nodes and 221424 units. The time step is 0.25 . The temperature monitoring points measured by optical fiber and used by the backanalysis are DT01 DT07. Figure 5 shows the position of the above points.

The sensitive thermal parameters for the temperature field prediction are selected as reversed parameters, including three parameters $(\theta, a$, and $b)$ of compound index formula of adiabatic temperature rise, thermal diffusivity $\alpha$, and surface heat transfer coefficient $\beta$. According to the temperature data measured by DTS and the initial range of the above parameters, the back-analysis is performed. The thermal diffusivity and surface heat transfer coefficient are shown in Table 3. The adiabatic temperature rise formula is expressed as

$$
\theta(\tau)=21.40\left[1-\exp \left(-0.40 \tau^{1.10}\right)\right] .
$$

According to laboratory test results, the transient elastic modulus, autogenous volume deformation, and creep of the dam concrete can be fit as (12), (13), and (14), respectively.

$$
\begin{aligned}
E(\tau)= & 45.33\left(1-e^{-0.16 \tau}\right), \\
V(\tau)= & 26.65\left(1-e^{-0.01942 \tau^{0.87}}\right), \\
C(t, \tau)= & \left(1.447+88.562 \tau^{-0.803}\right)\left[1-e^{-0.183(t-\tau)}\right] \\
+ & \left(0.406+12.022 \tau^{-0.232}\right)\left[1-e^{-0.008(t-\tau)}\right] .
\end{aligned}
$$

Then the feedback analysis of temperature is performed with the concrete thermal parameters obtained by the backanalysis. Figure 12 shows the temperature process curves measured by DTS and the temperature process curves calculated by FZFX3D. It can be seen from Figure 12 that the 

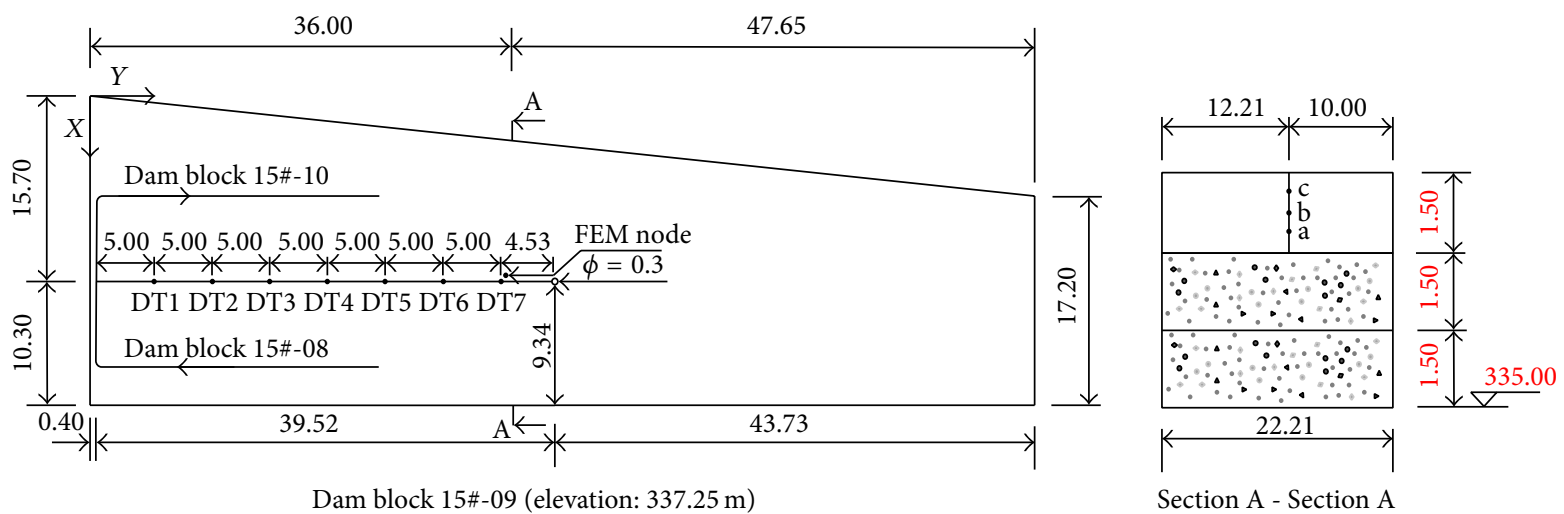

FIgURE 5: Position of cable and location of analysis nodes (unit: m).

TABLE 3: Thermal and mechanical properties of materials

\begin{tabular}{|c|c|c|c|}
\hline Type of properties & Parameter & Concrete & Bedrock \\
\hline \multirow{5}{*}{ Thermal properties } & Specific heat $c\left[\mathrm{~kJ} /\left(\mathrm{kg} \cdot{ }^{\circ} \mathrm{C}\right)\right]$ & 0.86 & 0.76 \\
\hline & Thermal conductivity $a\left[\mathrm{~kJ} /\left(\mathrm{m} \cdot \mathrm{d} \cdot{ }^{\circ} \mathrm{C}\right)\right]$ & 184.9 & 360.0 \\
\hline & Thermal diffusivity $\lambda\left(\mathrm{m}^{2} / \mathrm{d}\right)$ & 0.0758 & 0.1774 \\
\hline & Heat exchange coefficient $\beta\left[\mathrm{kJ} /\left(\mathrm{d} \cdot \mathrm{m}^{2} \cdot{ }^{\circ} \mathrm{C}\right)\right]$ & 1450 & 1450 \\
\hline & Adiabatic temperature rise $\theta\left({ }^{\circ} \mathrm{C}\right)$ & Transient & 20.5 \\
\hline \multirow{6}{*}{ Mechanical properties } & Density $\rho\left(\mathrm{kg} / \mathrm{m}^{3}\right)$ & 2663 & 2670 \\
\hline & Poisson ration $\mu$ & 0.17 & 0.20 \\
\hline & Linear expansion coefficient $\alpha\left(10^{-6} /{ }^{\circ} \mathrm{C}\right)$ & 7.0 & 6.0 \\
\hline & Elastic modulus $E(\mathrm{GPa})$ & Transient & 23.0 \\
\hline & Creep $C$ & Transient & None \\
\hline & Autogenous volume deformation $V$ & Transient & None \\
\hline
\end{tabular}

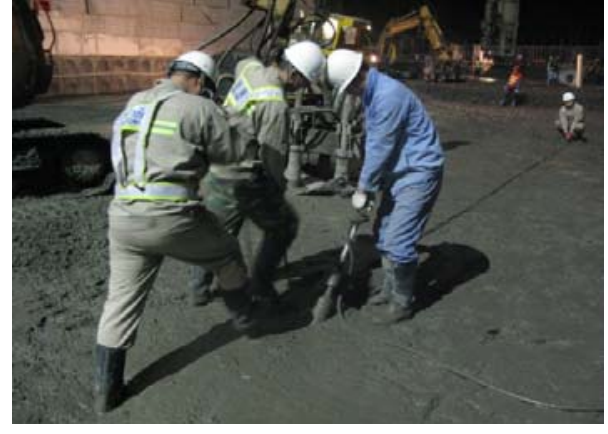

FIgURE 6: The burying process of cable.

calculation values match with measured values well, which means that the reversed thermal parameters are reliable and can be used to predict the temperature and thermal stress of $15 \#-10$.

3.3. The Splitting Tensile Strength of $C_{180} 40$ Concrete. To obtain the tensile strength of concrete, the splitting tensile strength of specimens, sampled from 14\#-01 concrete, is adopted, because the mix proportion of $14 \#-01$ is basically consistent with 15\#-10. When 14\#-01 concrete is casted, the splitting tensile strength of the concrete is tested by Changjiang River Scientific Research Institute (CRSRI), Test Center (TC), Xiluodu Project Department (XPD), and HydroChina Chengdu Engineering Corporation (HCEC), respectively. Figure 13 shows the results obtained from above 4 units. The data has a certain discretization. The fitting formula for the data is fit as

$$
\begin{aligned}
f_{t k}(t)= & 4.24657-0.77874 e^{(-t / 8.81743)} \\
& -0.79105 e^{(-t / 3.21387)}-2.67678 e^{(-t / 102.40503)} .
\end{aligned}
$$

3.4. The Determination of the Crack Risk Evaluation Principle. According to the calculation method given by Zhu [1], the allowed maximum temperature of the concrete is calculated by HydroChina Chengdu Engineering Corporation and then verified by the expert panel. Finally, the determined allowed maximum temperature is $27^{\circ} \mathrm{C}$. The anticrack safety factor obtained from Design Code for Concrete Arch Dam is 1.52.0. The crack risk level is shown in Table 1.

3.5. The Determination of the Preliminary Temperature Controlling Measures. To obtain the preliminary temperature 


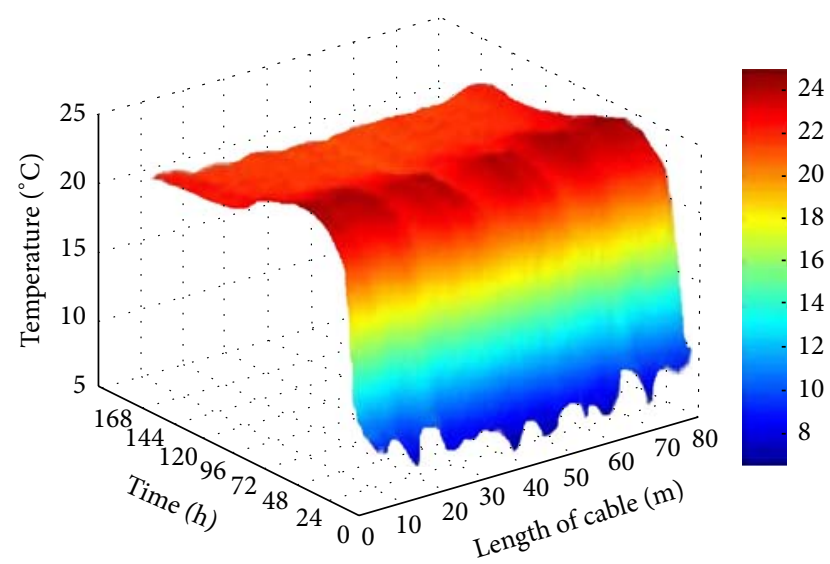

FIGURE 7: DTS measured temperature cloud.

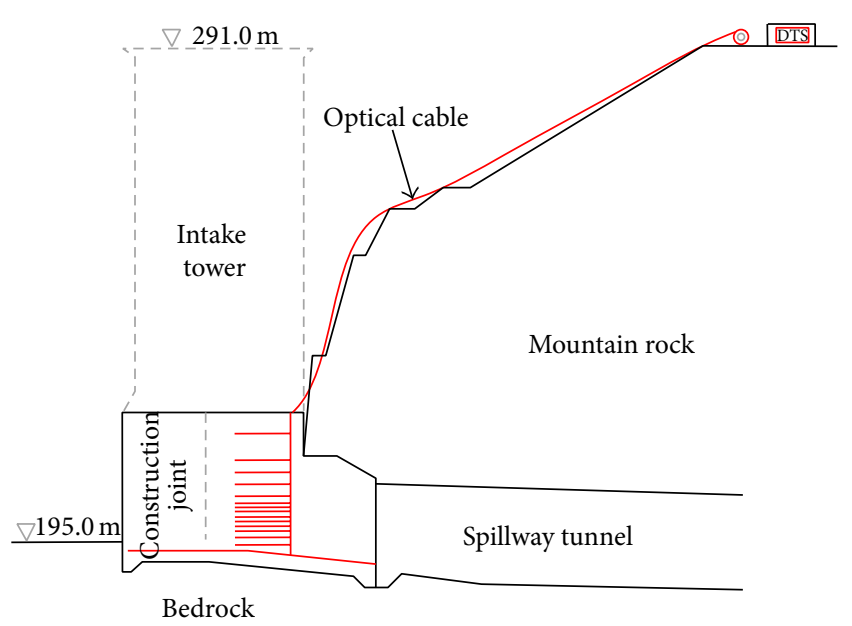

FIGURE 8: Overall layout of cable in the lateral view.

controlling measures, the temperature and thermal stress are predicted under three cases, based on the reversed thermal parameters and laboratory test results; the details of three cases are tabulated in Table 4.

Figure 14 shows the temperature process curves of three points under different cases. In three cases, the temperature of the concrete reaches the peak value in 3-5 days and then decline. As shown in the maximum temperature envelope of the block, the maximum temperature of the three cases is $31.57^{\circ} \mathrm{C}, 27.96^{\circ} \mathrm{C}$, and $25.69^{\circ} \mathrm{C}$, respectively, which means that controlling the casting temperature and burying cooling pipe play a significant role in reducing the maximum temperature. According to the indicator of crack risk evaluation principle, the allowed maximum temperature is $27^{\circ} \mathrm{C}$; thus, the maximum temperatures of cases 1 and 2 exceed the allowed value, while the maximum temperature of case 3 meets the requirement.

Figure 15 shows the thermal stress process curves of 2 points. The fitting curve of the splitting tensile strength is also plotted for comparison. The minimum anticrack safety factors of the three cases are 1.42, 3.06, and 1.55, respectively, and the corresponding crack risk levels are III, II, and II,

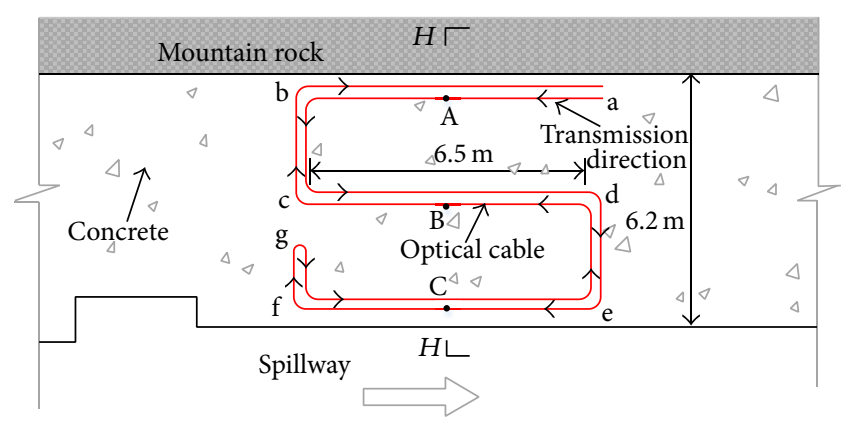

FIGURE 9: Layout of cable in the concrete block.

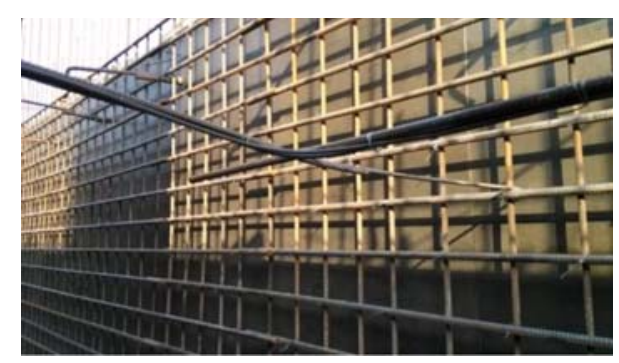

FIGURE 10: The optical cable fastened in the middle plane of the concrete block.

respectively, which means that the temperature controlling measures of cases 2 and 3 meet the anticrack requirement.

Under the two indicators of crack risk evaluation principle, the prediction of temperature and thermal stress shows that case 3 can be applied as the preliminary temperature controlling measures to guide the construction of $15 \#-10$.

3.6. The Determination of the Concrete Temperature Controlling Measures after Casting. 15\#-10 was casted completely in November 10, 2009. According to the meteorological data in the last 5 years, the temperature frequently dropped abruptly during this period, which easily leads to cracks of the early age concrete. Therefore, the concrete crack risk under this abnormal condition needs to be studied. In this part, the maximum temperature drop amplitude (the temperature continuously fell $16^{\circ} \mathrm{C}$ in 3 days and then returned to normal temperature) is adopted as the ambient condition to predict the temperature and thermal stress of the concrete. The predication cases are tabulated in Table 5.

Figure 16 shows the temperature process curves of two points ( $b$ and $c$ ) near the concrete surface when the weather is normal and temperature drops abruptly. Compared with the concrete temperature under normal weather, the abrupt dropping of temperature affects the temperature near the concrete surface significantly. The temperature drop of point $\mathrm{c}$ is the biggest and reaches $5^{\circ} \mathrm{C}$. After the concrete surface is insulated by polyethylene benzene plate, the temperature drop amplitude of the concrete is inversely proportional to the thickness of the polyethylene benzene plate.

Figure 17 shows the corresponding thermal stress curves of two points ( $b$ and c). When the temperature drops abruptly, 


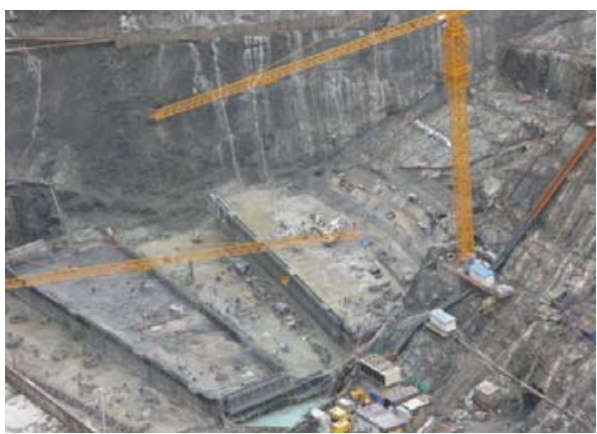

(a) Dam image

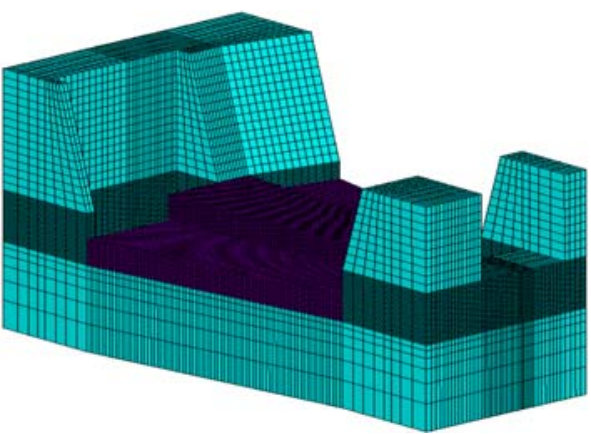

(b) 3D FEM model

FIgure 11: Image of Xiluodu Dam and 3D FEM model.

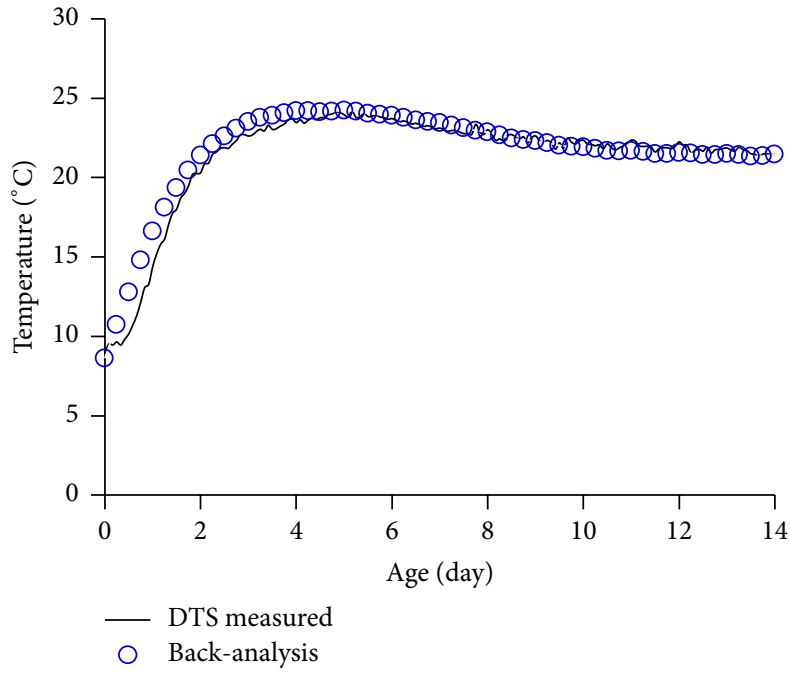

(a) DT01

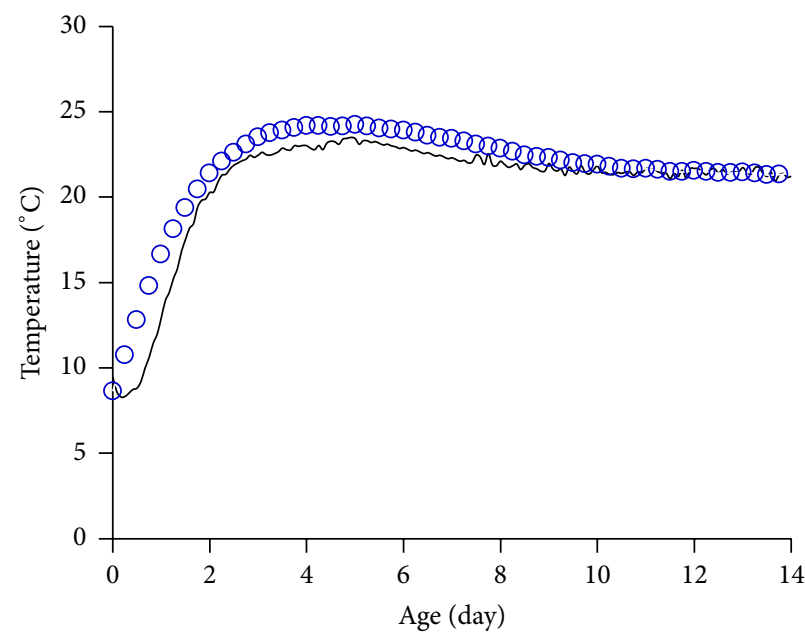

DTS measured
O Back-analysis

(c) DT05

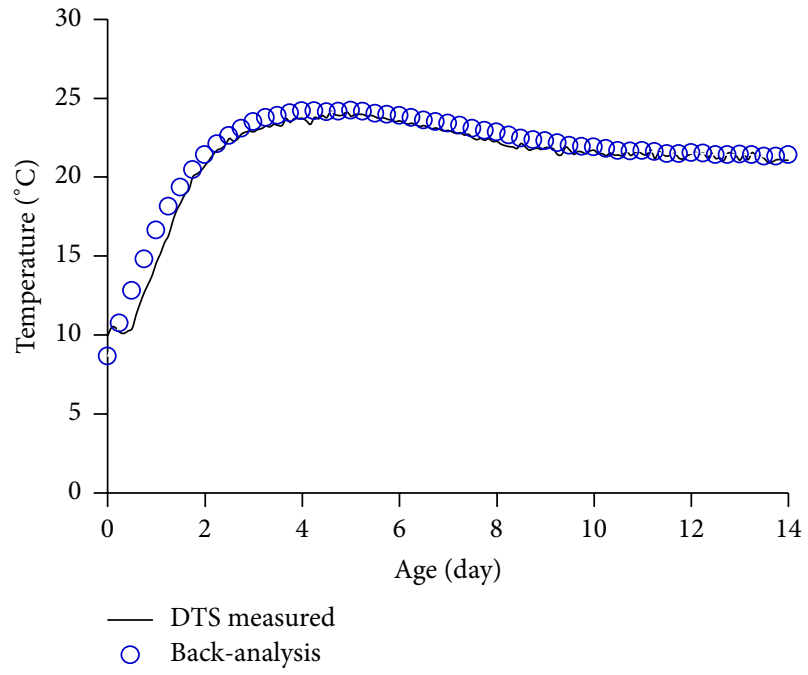

(b) $\mathrm{DT} 03$

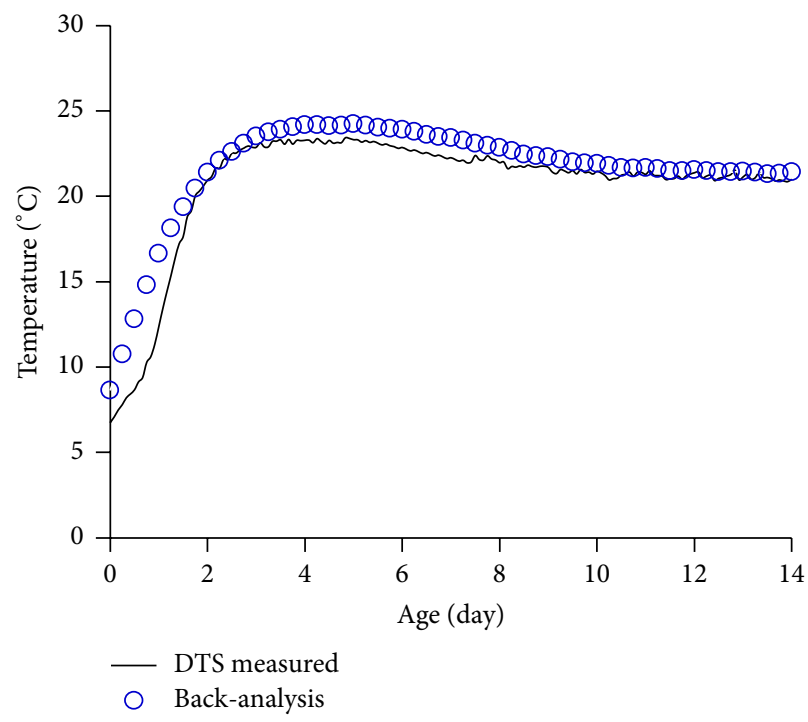

(d) DT07

FIGURE 12: Comparison of DTS measured temperature and back-analysis temperature. 


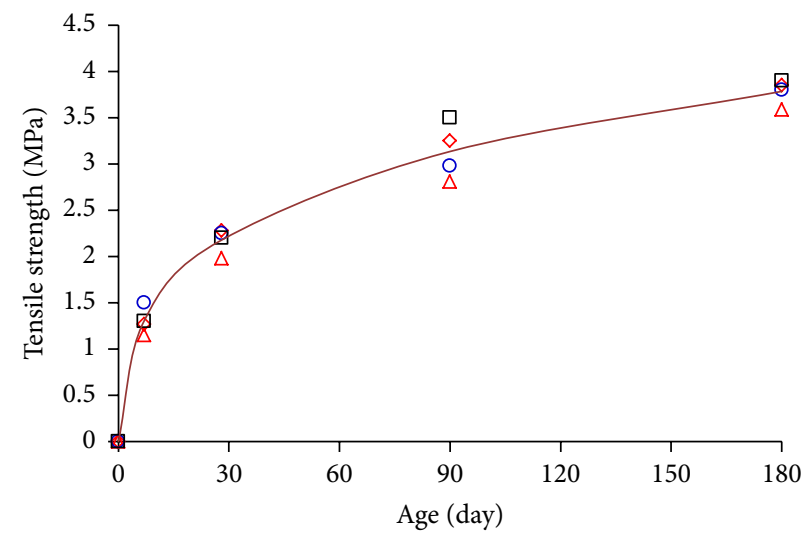
$\diamond$ CRSRI
口 HCEC
$\triangle \mathrm{TC}$
Fitting curve
○ XPD

FIGURE 13: The splitting tensile strength of the dam concrete.

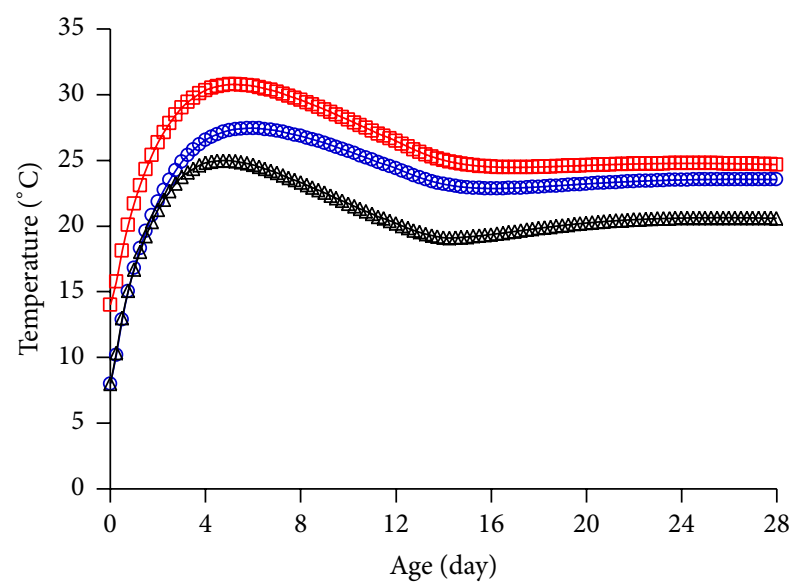

$\square$ Case 1

$\multimap$ Case 2

(a) Node a

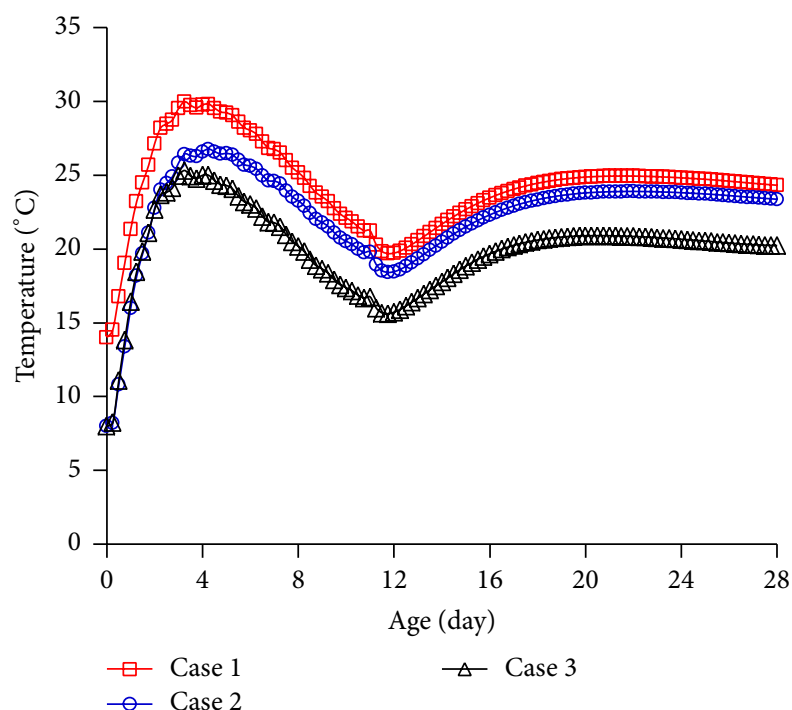

(c) Node c

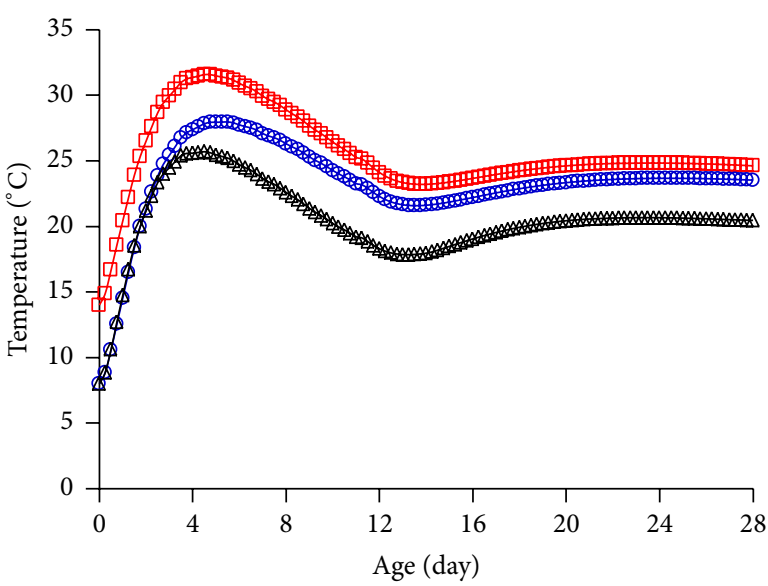

$\square$ Case 1

- - Case 2

$\triangle$ Case 3

(b) Node b

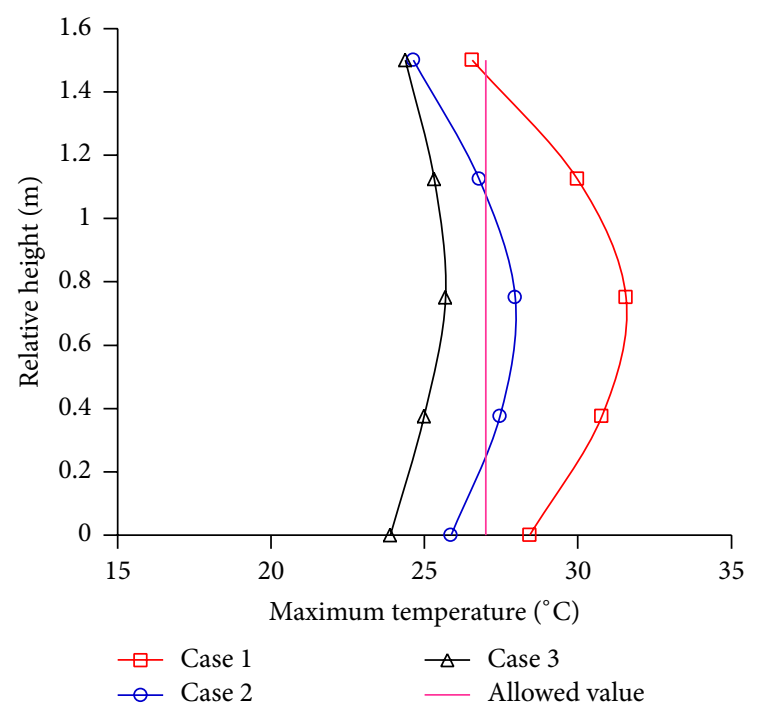

(d) Max temperature envelope

FIGURE 14: The temperature prediction results of typical points (nodes $\mathrm{a}, \mathrm{b}$, and $\mathrm{c}: x=16, y=36$ ). 


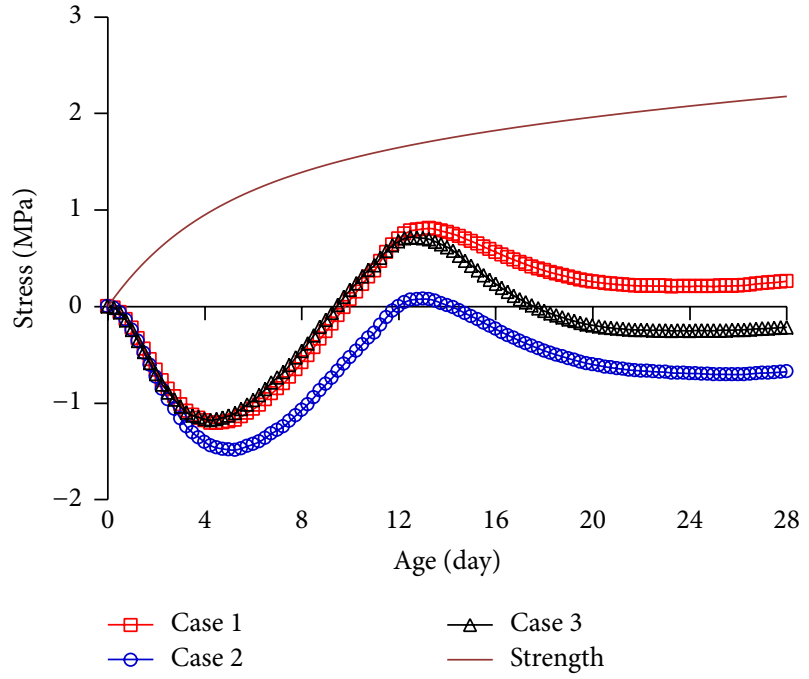

(a) Node b

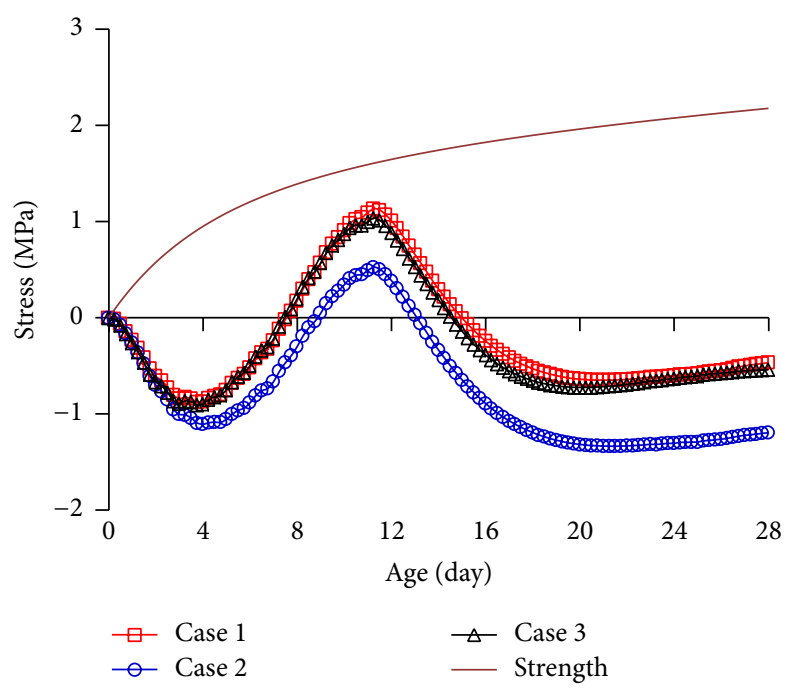

(b) Node c

FIGURE 15: The thermal stress prediction results of typical nodes.

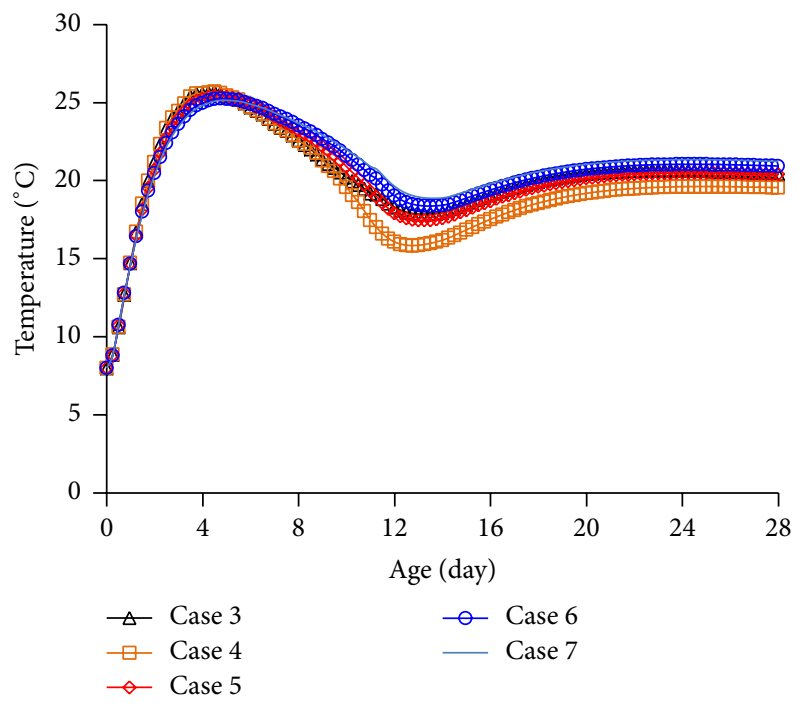

(a) Node b

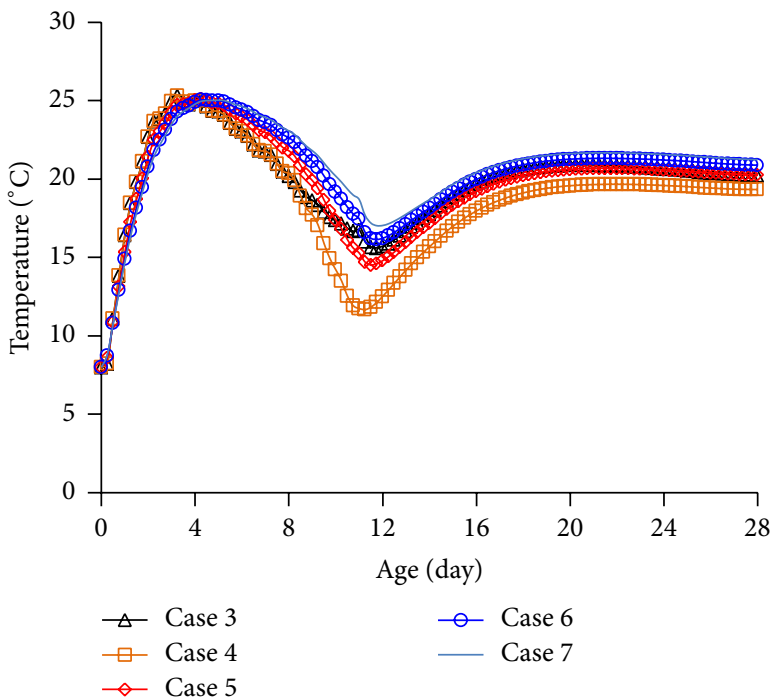

(b) Node c

FIGURE 16: The temperature prediction results of typical nodes.

TABLE 4: Temperature and thermal stress prediction cases at normal weather.

\begin{tabular}{|c|c|c|c|}
\hline \multirow{2}{*}{ Prediction cases number } & \multicolumn{3}{|c|}{ Possible temperature control measures } \\
\hline & Casting temperature $/{ }^{\circ} \mathrm{C}$ & Pipe cooling & Surface insulation \\
\hline 1 & 14 & None & None \\
\hline 2 & 8 & None & None \\
\hline 3 & 8 & $\begin{array}{l}\text { (i) Steel pipe } \\
\text { (ii) Vertical and horizontal spacing: } 1.5 \mathrm{~m} \\
\text { (iii) Outer diameter: } 32 \mathrm{~mm} \text {, thickness: } 2 \mathrm{~mm} \\
\text { (iv) Fluid water temperature: } 8^{\circ} \mathrm{C} \text {, discharge } 72 \mathrm{~m}^{3} / \mathrm{d}\end{array}$ & None \\
\hline
\end{tabular}




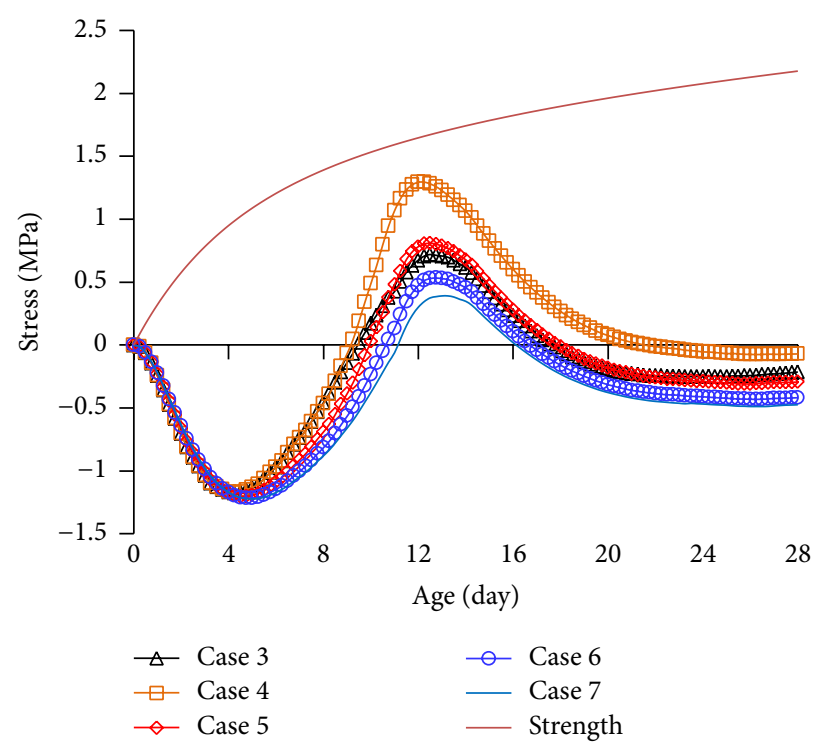

(a) Node b

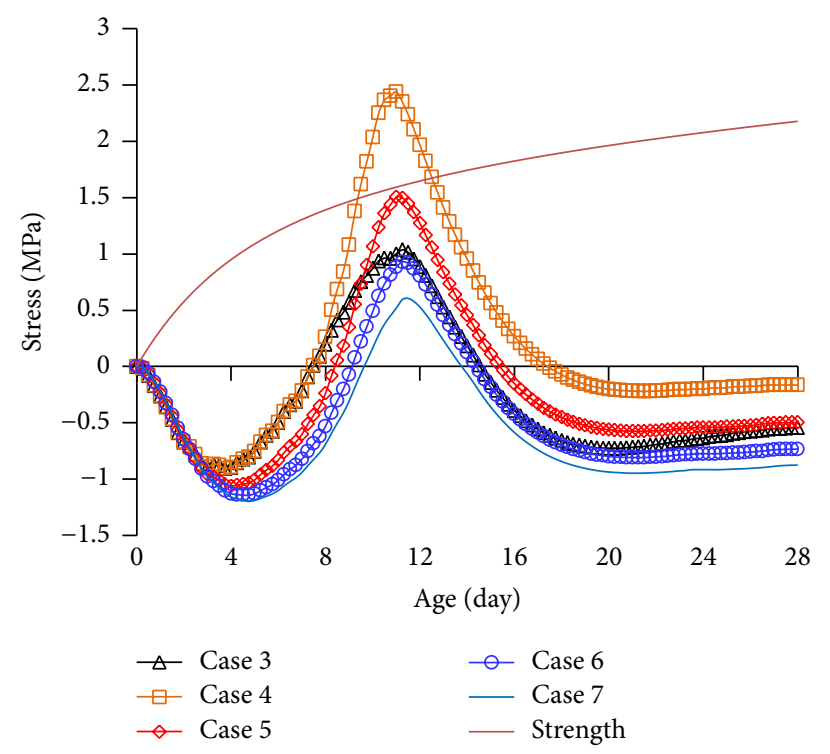

(b) Node c

FIGURE 17: Thermal stress prediction results of typical nodes.

TABLE 5: Temperature and thermal stress prediction cases at abnormal weather.

\begin{tabular}{|c|c|c|c|c|}
\hline $\begin{array}{l}\text { Prediction cases } \\
\text { number }\end{array}$ & $\begin{array}{c}\text { Temperature } \\
\text { drop amplitude } /{ }^{\circ} \mathrm{C}\end{array}$ & Protection material & Thickness/cm & $\begin{array}{c}\text { Equivalent thermal } \\
\text { exchange } \\
\text { coefficient } /\left[\mathrm{kJ} /\left(\mathrm{m}^{2} \cdot \mathrm{d} \cdot{ }^{\circ} \mathrm{C}\right)\right]\end{array}$ \\
\hline 4 & 16 & None & None & 1450 \\
\hline 5 & 16 & Polyethylene benzene plate & 2 & 624.8 \\
\hline 6 & 16 & Polyethylene benzene plate & 4 & 371.2 \\
\hline 7 & 16 & Polyethylene benzene plate & 6 & 264.0 \\
\hline
\end{tabular}

the temperature stress of point $\mathrm{c}$ is far beyond the concrete strength at the same age, while after making the insulation measures, the thermal stress reduces at varying degrees.

Table 6 shows the crack risk evaluation results of all cases. When the temperature drops abruptly, the crack risk level of case 4 is IV, which shows that its temperature controlling measures need to be reappraised; the crack risk level of case 5 is III, which shows that its temperature controlling measures have a certain reference value but do not meet the requirement against crack; the crack risk level of case 7 is I, which shows that its temperature controlling measures have a good insulation effect when the temperature drops abruptly, while, considering the higher cost of the thicker polyethylene benzene plate, the economy of case 7 needs further discussion. The crack risk level of case 6 is II, which shows that the temperature controlling measures are quite reasonable and more economical compared with case 7 .

To sum up, case 3 is recommended as the temperature controlling measures for $15 \#-10$ when the weather is normal and case 6 is recommended as the temperature controlling measures for 15\#-10 when the concrete block experiences abrupt temperature drops.

When construction of $15 \#-10$ is done under the proposed temperature controlling measures, no harmful crack appears, which suggests that the recommended temperature controlling measures are rational.

\section{Conclusions}

The crack risk evaluation system for the early age concrete is applied to recommend the preliminary temperature controlling measures before casting the new concrete block. When the casting process is completed, the system also provides temperature controlling measures to prevent the possible cracks caused by abnormal weather.

The prediction results of temperature and thermal stress, as well as the recommended temperature controlling measures of each concrete block, are uploaded in Xiluodu Dam Information System, which facilitate the exchange of views on the construction and also provide a guide for Construction Corporation.

The crack risk evaluation has been performed for 113 blocks of Xiluodu Dam by February 14, 2010. No harmful crack appears during the construction period, except for some cracks resulting from the lifting of consolidation grouting and short-time rainstorm. The crack of the early age concrete is common and difficult problem in the project. To 
TABLE 6: Crack risk evaluation level of 15\#-10.

\begin{tabular}{lcccccccc}
\hline \multirow{2}{*}{ Prediction cases number } & \multicolumn{2}{c}{ Node a } & \multicolumn{2}{c}{ Node b } & \multicolumn{2}{c}{ Node c } & \multirow{2}{*}{ Min $\left(K_{\min }^{\mathrm{a}}, K_{\min }^{\mathrm{b}}, K_{\min }^{\mathrm{c}}\right)$} & \multirow{2}{*}{ Risk level } \\
& $K_{\min }^{\mathrm{a}}$ & Age & $K_{\min }^{\mathrm{b}}$ & Age & $K_{\min }^{\mathrm{c}}$ & Age & 1.55 & II \\
3 & 3.99 & 14.00 & 2.32 & 12.50 & 1.55 & 11.25 & 0.65 & IV \\
4 & 2.27 & 14.00 & 1.27 & 12.00 & 0.65 & 11.00 & 1.06 & III \\
5 & 4.06 & 14.00 & 2.06 & 12.25 & 1.06 & 11.00 & 1.73 & II \\
7 & 7.34 & 14.25 & 3.16 & 12.75 & 1.73 & 11.25 & 2.68 & I \\
\hline
\end{tabular}

prevent the crack of early age concrete effectively, additional measures should be taken, such as improving the technique level of the construction teams, timely maintenance to prevent shrinkage, and improving the accuracy of abnormal weather forecast.

One thing should be noted that the mix proportion of adjacent concrete block is assumed to be unchanged. Under this circumstance, the reversed thermal parameters can be applied to predict the temperature and thermal stress of the new concrete block. When the mix proportion of the new concrete block changes, the thermal parameters should be reversed again and the splitting tensile strength adopted in the crack risk evaluation is also needed to be tested again.

At present, the crack risk evaluation system aims to provide temperature controlling measures for each new concrete block. When the data of crack risk evaluation is sufficient, the $3 \mathrm{D}$ model of the dam will be established and the crack risk evaluation of each block will be displayed dynamically in the Dam Informative System, which will definitely facilitate all units to grasp the state of the dam immediately.

\section{Competing Interests}

The authors declare that there is no conflict of interests regarding the publication of this article.

\section{Acknowledgments}

The authors would like to acknowledge National Natural Science Foundation of China for the financial support (ID: 51178014). The authors would like to thank Sinohydro Bureau 8 Co., Ltd. for their corporation during the burying of cable and also thank Changjiang River Scientific Research Institute, Test Center, Xiluodu Project Department, and HydroChina Chengdu Engineering Corporation for providing the splitting tensile strength test data.

\section{References}

[1] B. Zhu, Thermal Stresses and Temperature Control of Mass Concrete, China Electric Power Press, Beijing, China, 2003 (Chinese).

[2] F. Javanmardi and P. Léger, "Grouting of cracks in concrete dams: numerical modelling and structural behaviour," Progress in Structural Engineering and Materials, vol. 7, no. 4, pp. 161-173, 2005.
[3] F. Tanimola and D. Hill, "Distributed fibre optic sensors for pipeline protection," Journal of Natural Gas Science and Engineering, vol. 1, no. 4-5, pp. 134-143, 2009.

[4] G. Yilmaz and S. E. Karlik, "A distributed optical fiber sensor for temperature detection in power cables," Sensors and Actuators, A: Physical, vol. 125, no. 2, pp. 148-155, 2006.

[5] M. N. Amin, J.-S. Kim, Y. Lee, and J.-K. Kim, "Simulation of the thermal stress in mass concrete using a thermal stress measuring device," Cement and Concrete Research, vol. 39, no. 3, pp. 154-164, 2009.

[6] Y. Yuan and Z. L. Wan, "Prediction of cracking within early-age concrete due to thermal, drying and creep behavior," Cement and Concrete Research, vol. 32, no. 7, pp. 1053-1059, 2002.

[7] A. K. Schindler, J. M. Ruiz, R. O. Rasmussen, G. K. Chang, and L. G. Wathne, "Concrete pavement temperature prediction and case studies with the FHWA HIPERPAV models," Cement and Concrete Composites, vol. 26, no. 5, pp. 463-471, 2004.

[8] M. Azenha, R. Faria, and D. Ferreira, "Identification of early-age concrete temperatures and strains: monitoring and numerical simulation," Cement and Concrete Composites, vol. 31, no. 6, pp. 369-378, 2009.

[9] S. M. Aminossadati, N. M. Mohammed, and J. Shemshad, "Distributed temperature measurements using optical fibre technology in an underground mine environment," Tunnelling and Underground Space Technology, vol. 25, no. 3, pp. 220-229, 2010.

[10] E. Hurtig, S. Großwig, M. Jobmann, K. Kühn, and P. Marschall, "Fibre-optic temperature measurements in shallow boreholes: experimental application for fluid logging," Geothermics, vol. 23, no. 4, pp. 355-364, 1994. 

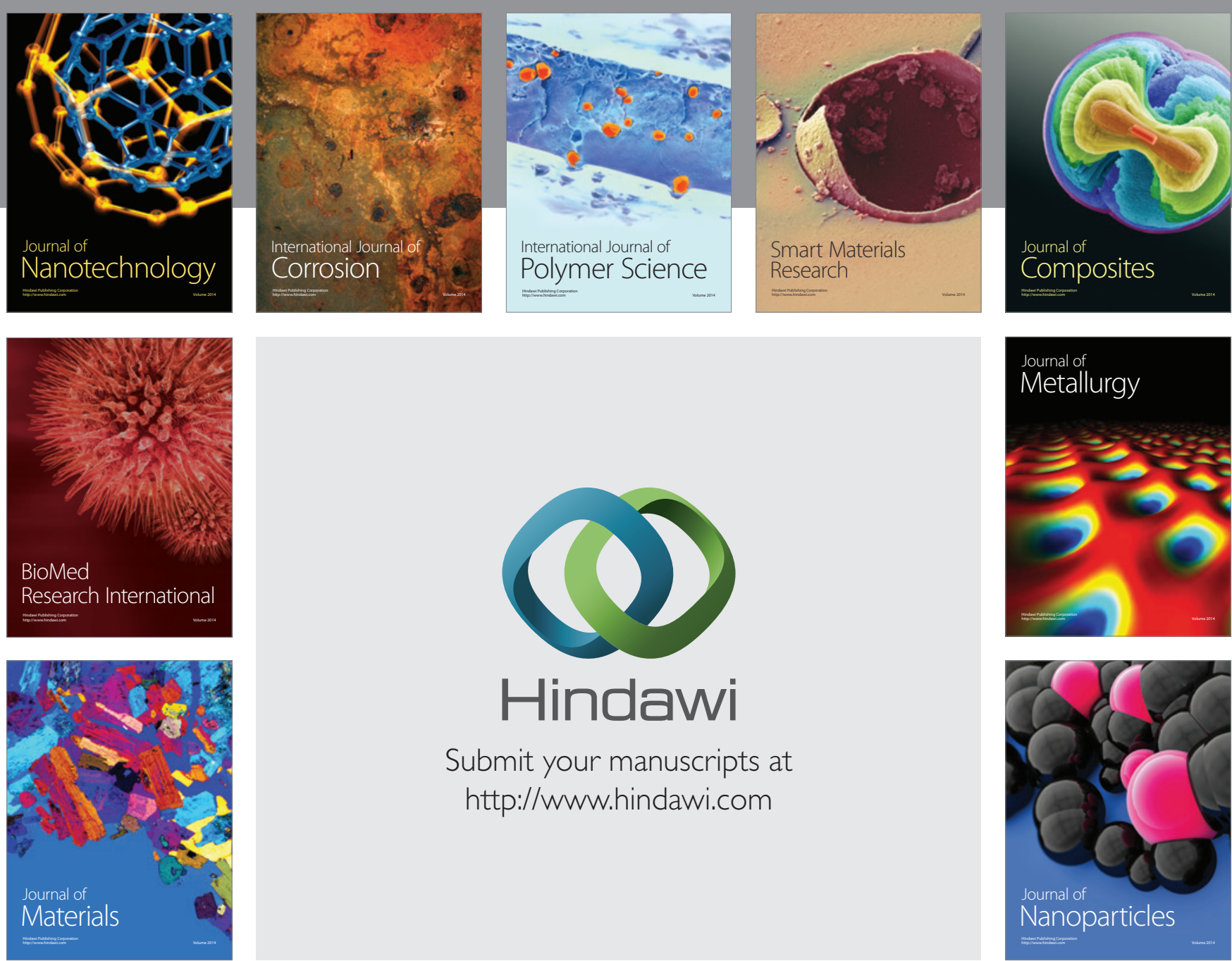

\section{Hindawi}

Submit your manuscripts at

http://www.hindawi.com

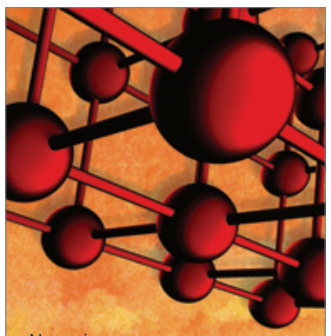

Materials Science and Engineering
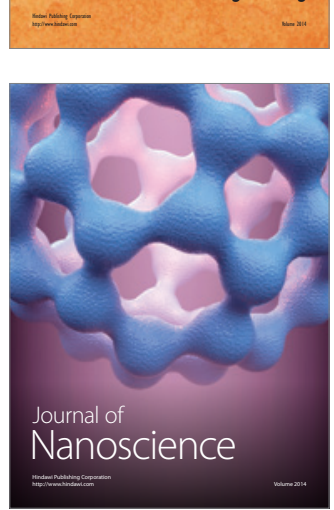
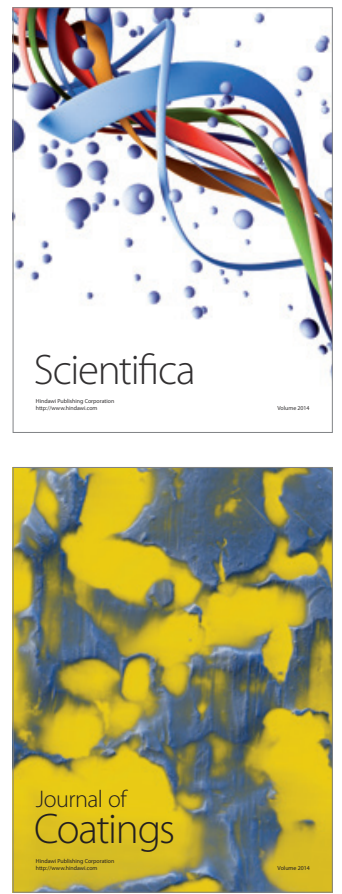
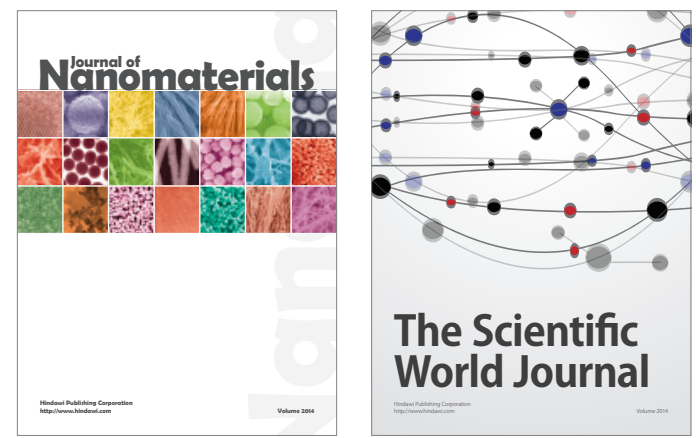

The Scientific World Journal
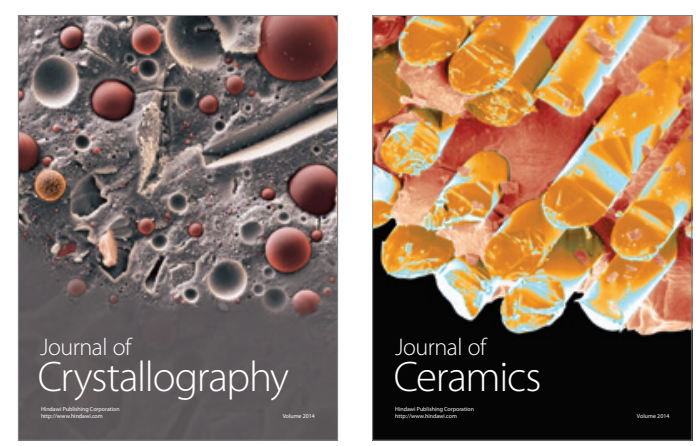
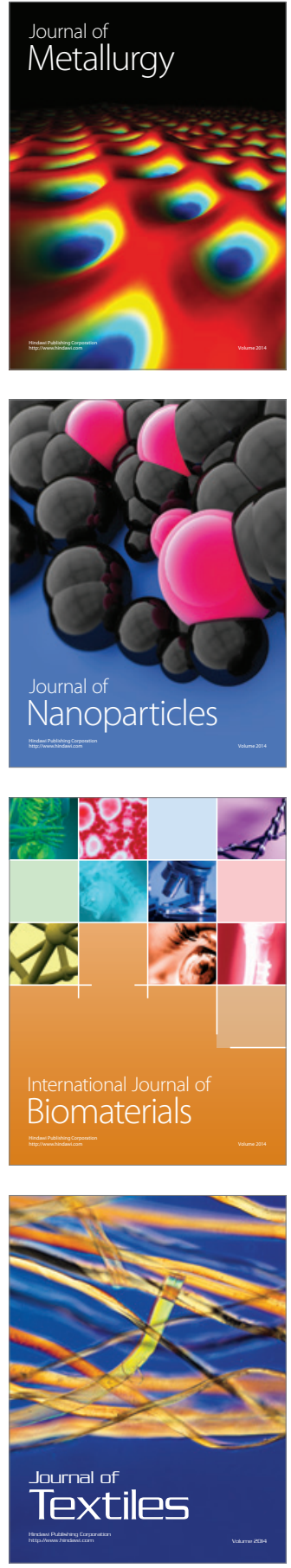